contains the report of an address by Dr. P. BrandtRehberg at the University of Copenhagen on "Science and Society", the report of an address by Dr. S. Tovborg-Jenson on world food problems, an address by Mr. Edmund W. Sinnott to the American Association for the Advancement of Science on the study of science by the amateur as well as one on the "Encouragement of Science" by Dr. J. R. Oppenheimer. Impact may be obtained from the Natural Seience Department, Unesco, 19 Kleber Avenue, Paris 16, price $2 s .6 d$.

\section{Industrial Fluorosis}

Memorandum No. 22 of the Medical Research Council, entitled "Industrial Fluorosis" (pp. 131 + 13 plates; London: H.M. Stationery Office, 1949 ; $4 s$. net), is a report made by the Fluorosis Committee of the Council. Its contents cannot be summarized in detail here; but it records a study of possible effects upon man and animals of the large amounts of fluorine liberated from a factory near Fort William, Scotland, engaged in the manufacture of aluminium by an electrolytic process. Part 1 of the report discusses the contamination by fluorine compounds of the area studied; Part 2 the effects of fluorine compounds on animals in this area ; Part 3 the clinical, radiological, hæmatological and biological studies of human beings ; Part 4 the dental condition of adults and school children in the area; and Part 5 the physical properties of bone in fluorosis. Appendixes, which summarize the literature on the toxicity of fluorine compounds and describe the analytical methods used, and the bibliography extending to more than four pages of small type, add to the value of this comprehensive study.

\section{Wounds of the Extrt...ities during the War}

THE British Journal of Surgery is publishing, in four supplements, a permanent record of the achievements of British surgeons during the Second World War. "War Surgery Supplement No. 1" appeared in 1947 and dealt with "Wounds of the Head" (see Nature, 161, 635; 1948). No. 2, edited by H. J. Seddon (pp. 26I-347; Bristol : John Wright and Sons, 1949. 12s. 6d.) bears the sub-title "Wounds of the Extremities", and it maintains the very high standard of the preceding supplement. An outstanding feature of these supplements is the excellence of the photographic and coloured illustrations; and the text, although it is addressed mainly to surgeons, will also interest others. Supplement No. 2 deals with war injuries of the extremities in the forward areas of battle, missile wounds involving bone, the early treatment of penetrating wounds of joints, and war injuries of peripheral nerves and arteries. The methods used and the remarkably successful results obtained by modern surgery will interest anatomists and physiologists as well as surgeons. The other two supplements, which will deal with abdomino-thoracic wounds and plastic surgery respectively, should prove equally interesting. It is good to know that the skill of the surgeon is being recorded permanently in this remarkable series of publications.

\section{New Methods of Glasshouse Fumigation}

THREE modern methods of pest control by fumigation are reviewed by Mr. G. Fox Wilson in a recent short paper (J. Roy. Hort. Soc., 74, Pt. $10 ; 1949$ ). Insecticidal smokes, produced by igniting pyrotechnic mixtures containing DDT, 'Gammexane' or 'Azo- benzene', provide a very convenient method, but are apt to damage plant foliage near the generator. The amount of insecticide which condenses upon the leaves is not, moreover, by any means standard. Production of aerosols by atomization under pressure is also convenient, and probably less toxic to foliage. The use of continuous-flow aerosols, however, provides a very promising and practical method. The insecticide is here evaporated slowly and continuously by electric heat. Mr. Fox Wilson describes the result of trials with such an apparatus at Wisley. Perhaps the outstanding effect was a speedy and effective control, with continuous-flow aerosol DDT, of the greenhouse white fly. Adults of this species died within twenty-four hours, and, though the eggs and nymphal stages were unaffected, the adults were destroyed soon after they were produced. Success was also obtained against mealybug, and, in part, against aphids (which are not generally controlled by DDT), and soft scale. Negative results were recorded against eucalyptus sucker and the carnation tortrix moth.

\section{Summer School in Mathematics at St. Andrews}

A Mathematical summer school was held at St. Andrews during June 30-July 8, under the auspices of a group of mathematicians from the four Scottish Universities. It was attended by about forty university teachers and research students. After an opening lecture by Prof. H. W. Turnbull, on "Algebra and Algebraists", courses of lectures were delivered on "Group Representations", by Dr. D. E. Rutherford, of St. Andrews, on "Linear Associative Algebras", by Dr. W. Ledermann, of Manchester, and on "Topology", by Mr. A. G. Vosper, of Dundee.

\section{I Exhibition Scholarships}

THE Royal Commission for the Exhibition of 1851 announces the award of Overseas Science Research Scholarships for 1950 to the following: Canada: W. L. Davison (Dalhousie University, Halifax, Nova Scotia), for research in geology in the University of Edinburgh ; N. R. F. Steenberg (Queen's University, Kingston, Ontario), for research in nuclear physics in the University of Oxford; R. M. Stow (University of Saskatchowan), for research in physical chemistry in the University of Cambridge. Australia : F. A. L. Anet (University of Sydney), for research in organic chemistry in the University of Oxford ; P. J. Fensham (University of Melbourne), for research in physical chemistry in the University of Bristol ; L. M. Jackman (University of Adelaide), for research in organic chemistry in University College, London; P. M. Nossal (Univorsity of Adelaide), for research in biochemistry in the University of Sheffield. New Zealand: L. S. Wolfe (University of New Zealand), for research in animal physiology and biochemistry in the University of Cambridge. India : R. C. Sahney (University of the East Punjab and National Physical Laboratory, Delhi), for research in physical chemistry in the University of Cambridge. Pakistan : R. Ahmad (University of the Punjab), for research in chemistry in the University of Cambridge or London. Republic of Ireland: S. R. Duff (University of Dublin), for research in organic chemistry in the University of Oxford.

\section{Leverhulme Research Fellowships, 1950}

AWards for research, tenable for periods up to two years, have been made by the Leverhulme Trustees to the following, among others, for work 